\title{
Analyzing order: social structure and value in the economic sphere
}

\section{Patrik Aspers}

To cite this article: Patrik Aspers (2008) Analyzing order: social structure and value in the economic sphere, International Review of Sociology - Revue Internationale de Sociologie, 18:2, 301-316, DOI: 10.1080/03906700802087894

To link to this article: https://doi.org/10.1080/03906700802087894

曲 Published online: 17 Jun 2008.

Submit your article to this journal ¿

Џ Article views: 145

Q View related articles $\widetilde{ }$

4 Citing articles: 2 View citing articles 


\title{
RESEARCH ARTICLE
}

\section{Analyzing order: social structure and value in the economic sphere}

\author{
Patrik Aspers* \\ Planck-Institut für Gesellschaftsforschung, Cologne, Germany, and Sociology, Stockholm University, \\ Stockholm, Sweden
}

(Received March 2007; final version received 3 September 2007)

\begin{abstract}
The purpose of this article is to analyze social order in the economic sphere. This is done by introducing social configurations as a theoretical notion. Configurations combine social structure of interfacing roles with values. The type of configurations studied here are markets, the most central mechanisms in the economic sphere. It is claimed that any market analysis must account for social structure as well as values. The main argument of this article is that the same type of social structure can demonstrate different underlying values and logics in the economic sphere. This is shown in four empirical examples of markets.
\end{abstract}

Keywords: value; markets; structure; economy

\section{Introduction}

The purpose of this article is to analyze social order in the economic sphere. By social order I mean how actors, positions, activities and rules are predictable, which is another way of saying that they are fairly stable in relation to each other (cf. Eisenstadt 1968, pp. 23-36). Order is studied using the theoretical notion that I introduce, social configuration. Configurations combine social structure of interfacing roles with values. The main argument of this article is that the same type of social structure can demonstrate different underlying values and logics in the economic sphere. The US-driven economic sociology has put much emphasis on social structure, but neglected the issue of value (cf. Emirbayer and Goodwin 1994, Fevre 2003). Configurations aim to rectify this value deficit in economic sociology, and especially in the sociology of market literature. This article addresses a debate in economic sociology (see Biggart and Delbridge 2004, pp. 30-31) between those stressing culture and values (e.g. Zelizer 1989), and those stressing structure (e.g. Burt 1992) to explain order in the economy.

Though the main point of this article is theoretical, the argument is empirically grounded in a discussion of real markets. The different empirical cases included should not be seen as unique phenomena; they can be understood as instances of configurations. The suggested approach enables us to deal with the multitude of real markets in a comprehensible way. Moreover, with markets as a baseline it is easier to interpret other social configurations.

To address the question of order in the economic sphere, and more specifically order in markets, I discuss how social structure and values are related. This calls for an analytic approach that separates structure from value, which, however, is a preliminary stage to gain

*Email: aspers@mpifg.de and patrik.aspers@sociology.su.se 
knowledge of the social phenomenon studied. The first section of this article deals with social structure. Two types of social structure are identified, called switch role and fixed role respectively. The second section deals with values. The last section before the conclusion brings the two dimensions, structure and value together in four empirical cases.

\section{Social structure}

Radcliffe-Brown defines social structure as a 'complex network of social relations' (1952, p. 190). This definition is the starting point also in my work and it covers, for example, personal relations, defined as differentiation of individuals into social roles, such as sex or work roles, and memberships, for example, in kinship systems, as well as citizenship. The core of the definition is social relation, "between two or more individual organisms when there is some adjustment of their respective interest, by convergence of interest, or by limitation of conflict that may arise from divergence of interest' (Radcliffe-Brown 1952, p. 199). Actors, or as they sometimes are called, incumbents, hold positions in the social structure. An actor is here defined widely enough to include organizations (e.g. firms, cf. Burt 1992).

The classical definition of social relation is made by Max Weber (1978) [1921-1922]). Weber defines social relations as "the behavior of a plurality of actors insofar as, in its meaningful content, the action of each takes account of the others and is oriented in these terms' (1978 [1921-1922], p. 26). This means, following Weber, that there must be at least some mutual orientation from ego to alter ego(s). This relation, I claim, must be grounded in the meaning as it is perceived by those involved in the relationship.

Social structure is a result of habituation of interaction. This means that certain structural positions, such as roles in markets, are results of past interaction, which, so to speak, have coagulated. A role must be 'objective', in the sense that it is known by many people, all of whom attach virtually the same, 'socially defined appendage of knowledge' to it (Berger and Luckmann 1966, p. 78). The construction of a social role exemplifies this. A role emerges out of repeated social interaction, and what from the beginning was unclear, and may have varied, has gradually become stable, ordered, and predictable. For roles to become typified actions, people must first be aware of them, so that they can use, interpret and orient their actions to them. Over time people take these roles and positions and their expected behavior for granted because they are part of the common knowledge of social actors (cf. Berger and Luckmann 1966). Thus, a role, such as a policeman, is partly defined in terms of relations to others (politicians, criminals, and fire fighters), and partly in terms of interests or values (diminishing crime, and supporting the public). Through his actions the policeman also represents a social institution, the law (Berger and Luckmann 1966, p. 75).

Social structure is usually relational, but also 'substantial' in the sense that positions are also defined in terms of the values they carry. One may refer to this phenomenon as structured values. ${ }^{1}$ That is, values can both become part of the structure, and thereby more likely to be sedimented, and even forgotten, but they may also exist rather independently of a certain type of social structure, and in this case not be seen as part of the structure. The important issue, which will be addressed below, is that given a certain structure, which from here and onwards includes structured values, different concrete values may be central.

\section{Towards configurations}

Is it then not enough to explain social phenomena using merely the idea of structure? The short answer is 'no'. There are several shortcomings with scientific approaches that focus 
only on positions, i.e. structural approaches. One of them is that they may be phenomenologically false. Whether an actor identifies with a position or not is important if one wants a phenomenologically sound account of the human conditions under scrutiny (Aspers 2005a). As will become clear, the structural conditions in all economic configurations (markets) are identical from a purely objectivistic point of view, that is, there are two distinct roles (positions), e.g. buyers and sellers, in any market transaction. But some actors constantly shift roles, so that they, for example, are buyers one second and sellers the next, whereas actors in other markets are completely and permanently identified with one role in the market (i.e. as buyer). In the approach I use the identification of actors with a role as a central aspect (cf. Aspers 2005b).

I claim that a scientific account must accommodate the phenomenological insights, i.e. the structure as perceived by the actors involved, instead of following the natural-science approach to social structure advocated by Radcliffe-Brown (1952) and others. ${ }^{2}$ An explanation demands more than a story; an explanation must include accounts of accounts, i.e. theoretical notions that nonetheless are connected to the accounts of the actors (Aspers 2005a).

Configurations can be separated according to different social structures. There are two ideal types (kinds) of structures, switch and fixed role structures, which will be exemplified below. I will let markets exemplify each type. ${ }^{3}$ In the switch role structure incumbents of roles are oriented to each other, and demarcated into two sides with different interests. There is also a relation to actors on the same side. The actors, organizations or individuals, can, and often do, change side (role) in the configuration. Though each side is defined in terms of similarity, there is also a structural relation to actors on the same side, characterized by difference. Actors on the same side may struggle (compete) to achieve their ends. Furthermore, there is a value, which may be beauty, friendship, quality (in a variety of ways) that underlies the configuration. This is the general description, but it can be made more easily understandable if related to concrete configurations, for example markets.

Economic actors, such as individuals and firms in a switch role structure, may switch roles so that one first is a buyer and later a seller of the same or another item. Swap meetings, financial markets, and stock exchange markets are examples of switch markets. ${ }^{4}$ In these situations actors are not fixed to only one role in the configuration, instead they constantly switch roles, and actors are neither identified as sellers or as buyers, they are simply 'market actors'.

In the fixed role structure incumbents of the roles are oriented to each other, and demarcated into two sides with different interests. This, however, does not set it apart from the switch structure. There is also a relation to actors on the same side. What sets it apart from the switch structure is that actors only hold a role on one side of the configuration. Thus, actors are identified with a role. There is also a value that underlies this kind of configuration. Most real markets are role markets (Aspers 2005a). Shoe manufacturers, for example, only hold the role as producers of shoes; they do not also operate as consumers of shoes. $^{5}$

It is clear, however, that the social structure does not determine the competitive logic in markets (or the lack of it). One switch market, the foreign currency market in the streets of Istanbul, may be as competitive as a role market, the global garment market. And another switch market, a swap meeting for train models, may be as friendly as a role market, the fair-trade market for garments. In other words, social structure is not enough to explain the differences of real markets. In fact, the social structural approach is always in trouble when facing different outcomes of identical social structure. 


\section{Value}

Structure, including structured values, is essential for social configurations. Value is another key aspect, and culture, including the name of the configuration, together with its language, style, and history makes it unique. This section deals with values, and in the next section value and social structure in markets will be brought together. My discussion of value does not refer to the price process and the economic value. My point is that the underlying values of configuration can be of many kinds, all of which have prices in economic terms.

Both Radcliffe-Brown, who speaks of interest (1952, p. 199), and Weber (1978 [19211922]), who speaks of meaning and interest, connect social structure with values. Meaning and interests signal that there is something that is valued. But what is the meaning of value and the correlated notion of evaluation? Values are here defined as 'any point of view specifying which consequences of action are to be preferred to others' (Luhmann 1982, p. 97). This definition states that evaluation is intimately connected to value. Thus, values inform us what is good or bad; they guide people, and make them prefer one thing (states) to another (cf. Luhmann 1995 [1984], p. 317). The connection implies that each value is, at least, indirectly related to other values. ${ }^{6}$

Values are important in all sociological analysis, including sociological analysis of markets, for explaining order (cf. Devereux 1961, p. 23, Joas 1997, pp. 32-34). Moreover, individuals have goals and are oriented to values. Parsons argues that one can analyze, i.e. separate, society into different social sub-systems. Each such system is characterized by its own value. This makes is possible to speak of value systems, which Parsons claims 'consists in a complex of normative cultural patterns which define desirable states, including directions of change, of the social system in question' (1991, p. 37). Moreover, Parsons, like Radcliffe-Brown, connected values and social structure (Lidz 1991, p. 31). Parsons argued that a society is defined in terms of its unifying value (Devereux 1961, p. 36), which normally is the most dominating sub-system. This means that economic values may be fundamental in societies, which Parsons claimed to be the case in the US.

Parsons correlates the idea of consensus with functions of each sub-system. This correlation is erroneous, and a reason why his theory became obsolete. But stripped of consensus and functionalism, his ideas of values and sub-systems are useful. Values contribute to creating stable social configuration, and they may also help people to maneuver in society. However, that a configuration is connected with a value must not be read as a functional argument (cf. Joas 1997, pp. 17-18). A configuration may not fulfill a function for society or any other unit, and it may not be the result of one single designer.

How does one identify values? The classical idea is that values are internalized through processes of socialization. Socialization never ends, and even grown-ups learn to internalize new values. People can handle the diversity of real life, including the conflicting values of the different spheres of life, or provinces of meanings, by acting differently in different situations (Becker et al. 1961). Hence, interaction in the family sphere and interaction in markets can be guided by different values.

According to Parsons and Weber, values are part of what constitute motives of actions. We cannot observe values directly, and as a consequence, I will talk of actions driven by values. It follows that empirical work is needed in order to study values. Values may not always operate at a conscious level. I would not say that they thereby operate unconsciously, but values can become sedimented and function as a taken-for-granted background (cf. Husserl 1970 [1954]). 


\section{Economic values}

By value in markets I refer to the Parsonian notion of value, not the versions of neoclassical economics. Economic values of goods and services emerge in markets and are usually expressed in prices. The idea of prices in the neoclassical theory is built on the idea of marginal utility, developed by Jevons and others (Schumpeter 1981 [1954], pp. 825, 836). My focus, however, is not on this form of economic values expressed in prices that one finds in any market, but on the values that make configurations, including markets, different. Broadly speaking this focus refers to the competitive logic of markets.

There are many kinds of values, religious, political, ethical, but to make my point easier to grasp, I continue to focus on the economic sphere, in practice markets. I will in this section talk about economic values, and in particularly capitalistic values. Real markets show a variety of underlying values. ${ }^{7}$ One may identify highly competitive capitalistic markets at the one end, and non-capitalistic markets at the other end. Capitalism can be described as 'accumulation of wealth', which implies profit-making. To this one may add various aspects, such as private ownership. This description, however, covers situations found in virtually all kinds of societies.

Consequently, there are other values that can sustain a market than capitalistic ones. This, of course, is not to deny that actors in a market are there to trade, but that what is valued in the market may not necessarily boil down to capitalism. Karl Polanyi (cf. 1957) shows how pre-market trade implies the existence of a social foundation, including values, of the activities taken place in trade. This is just one example of traders, who essentially do not operate according to the capitalistic logic and its values (cf. Gudeman 2001, pp. 5-9).

Max Weber developed the best-known scientific theory of capitalism, which of course must be seen in relation to the theories developed by another German, Karl Marx. Weber acknowledges that various types of capitalism existed long before the Western rationalistic type emerged, for example in China, India, and mediaeval Europe. Thus, Weber (1978 [1921-1922], pp. 164-166) distinguishes between several forms of capitalisms, such as political authoritative and predatory, each with different forms of profit opportunities (cf. Swedberg 1998).

Weber defines a (rational) capitalistic action 'as one which rests on the expectation of profit by the utilization of opportunities for exchange, that is on (formally) peaceful chances of profit' (1968 [1904-1905], p. 17). One important aspect of capitalistic actions is calculation, and the other is the market, which is a precondition for calculations.

The process Weber describes means that money, eventually, was seen as an end (value) in itself, and this fundamentally changed the values of society. A consequence is that people did not merely make some money and then settle down. Capitalism also implies, according to Weber, that people accumulate money, reinvest it in industries, and thereby boost the economy.

Capitalism is part of what defines the economic sphere, which is characterized by instrumental rationality, impersonal exchange, depersonalization, objectification, universal measures, calculus, and formal contract (Weber 1946, pp. 331-333, 1978 [1921-1922]). The capitalistic logic is underpinned by values, such as acceptance of wealth, instrumental rationality, impersonality and so on. These values justify capitalistic actions and accumulation of wealth according to the rules of capitalism. Furthermore, wealth is unequivocally equated with money, or something that can be easily measured in terms of money. Capitalism, though there are many forms, is a form of economic logic.

Ultimately, capitalism is both a practice for how to do things, but also an ethical discourse for legitimating actions. This indicates that both values and social structure can 
bring about order. The approach presented here does not give a priori priority to any of these or another form. Finally, values are in practice not independent, but related in a web of values. This means that a more thorough sociological analysis may study this web of values, rather than focusing on a single value.

\section{Value and structure}

So far I have discussed social structure and values, specifically different kinds of values in the economic sphere, focusing on capitalistic values. The approach has been analytic. It is now time to make a synthesis of value and structure; this also means to get closer to reality, where value and structure appear in concert. Attempts exist to relate values to structure. I will here discuss Biggart and Delbridge, White, and Bourdieu. There are obviously other candidates, such as Karl Polanyi, but the main idea is not to review the literature, rather to make a theoretical point.

Biggart and Delbridge (2004) make a classification of economic interaction based on what they call systems of exchange. In this respect they follow Parsons, who tried to create an 'extra-theoretical framework' for economic theory (Parsons 1961, p. 316). Their idea is that the basis of action can be divided into two kinds: instrumental (means-oriented) and substantive (value-oriented) rationality; this is essentially a Weberian idea. The other dimension, social structure, can also be divided into two kinds: universalistic (all actors are treated the same way), and particularistic (one group is treated differently from others). This idea originally comes from Parsons. By combining these dimensions they get four systems of exchange, and each one 'assumes a characteristic logic' (Biggart and Delbridge 2004, pp. 36, 42). Given their scheme, it is clear that the neoclassical market exchange system is only one among many such systems.

However, this scheme is, in my opinion, not satisfactory. The analysis is simply made at the level of systems of exchange, which is their own invention. Though they admit that the system is hypothetical (Biggart and Delbridge 2004, p. 36), one may wonder why it had to be invented in the first place. They make, in my opinion, the same mistake as Parsons did, reifying systems that lack empirical links. Are there concrete examples of exchange systems? If I understand it correctly, the US represents one, and the Scandinavian countries - which they apparently see as identical - represents another, and 'two different economic logics are reflected in the exchange systems of each society' (ibid.). Hence, Biggart and Delbridge argue that in the US 'economic independence is the dominant orientation for both individuals and firms', and in the Scandinavian economies, 'individuals and firms are oriented toward corporatism, a system that includes elements of social welfare and group organization' (2004, p. 36) In reality, one may of course find markets in a Scandinavian country that are as competitive as any market in the US. Their theoretical approach is to some extent empirically grounded, but when used there is a risk of committing the ecological fallacy. The notion of system leads the analysts to focus on systems that lack empirical references, or show apparent internal inconsistencies, which obviously is not what we expect from a sociological category. Furthermore, their approach fails to make a clear distinction between values (culture, or logic) and social structure. They acknowledge that their 'typology' is static. To come closer to a way of identifying the boarders between the economy and other parts of a society, one must theorize at a level that is empirically sound.

The work by Harrison White (1992) is useful given these requirements. White (1992) has presented an approach built around a number of molecules of social structure. He talks of three forms of social molecules: arena, interface and council. All actors in an arena, for 
example, the stock exchange market, are identical, "rather than "marked" by side and fixed in niche by quality', which is the case of interfaces (White 1992, p. 52). Interfaces are exemplified by producer markets. Most of White's work (e.g. 1981, 2002), both theoretically and empirically, focuses on the interface. The council is represented by 'disciplines centered on a process of balancing contending but ever-shifting coalitions' (White 1992, p. 31). Moreover a council can be characterized as a process of mobilization, 'such as an annual in-gathering of a kinship group to reallocate turfs and settle disputes' (pp. 31-32). Examples are procurement and suppliers' networks. Production system for Hollywood films seems to be an example of the council species (p. 104). This notion, however, is not very well developed (p. 103). White's approach is promising, though not a complete theory. However, White has comparatively little to say about values. White describes a causal process, in which values come out of identities trying to control the chaos they find themselves in. The identities creating values are always enmeshed in social disciplines (pp. 138-139). White, however, says little on how the other actors, i.e. those on the other side of an interface affect the identity of the side the researcher studies.

Finally, I will mention Pierre Bourdieu's discussion on social structure and values, concentrating on markets. Bourdieu frequently talks about the market, though the relation between fields and markets is not entirely clear (e.g. 1984 [1979], pp. 85-86, 95-96, Bourdieu and Wacquant 2002 [1992], pp. 140-147). This is partly because the relations between fields are not clear, which Bourdieu and Wacquant (2002 [1992], p. 109) admit. Field is Bourdieu's equivalent to White's molecules, i.e. a tangible unit of analysis (Bourdieu and Wacquant 2002 [1992], p. 107). My interpretation is that a market connects two fields, or subfields, each of which has its own specific logic, or value (cf. Bourdieu and Wacquant 2002 [1992], pp. 97-98, Bourdieu 2005). What is valued in fields differ, depending on how the game of the field is played, and what kind of capital (and values) the winning side enforces.

Bourdieu indicates the relation between the two notions of field and market at several occasions. He says that the market is a relation between fields of production and fields of consumption (1984 [1979], p. 230). Thus autonomous fields, such as the literary or artistic fields (1990 [1987], p. 140), are partly constructed in relation to the market, i.e. in relation to the consumers. This issue is at the center of attention in Rules of art (1996 [1992]).

Both White and Bourdieu take a broad sociological approach and include markets as special cases of more general sociological categories. But Bourdieu also speaks of the inverted logic (of markets) and talks of different types of capital, and that actors calculate in markets (e.g. Bourdieu 1990 [1980], p. 112). Forms of capital can also be exchanged (Bourdieu 2001 [1983], pp. 98, 105-107). This means that two different 'markets' (in Bourdieu's sense) can differ in their degree of economic logic. In fact, a market may exist which revolves around symbolic, rather than economic (e.g. capitalistic) values (Bourdieu 1996 [1992], pp. 148-149). Thus, one must bring up the issue of value to understand markets and fields (p. 141). At a more abstract level, Bourdieu analyzes social order. The two sides of a market, 'production' and 'consumption', define each other and create order by generating two ranks of identities. Actors on each side, or each rank, hold positions that are fundamentally relative to each other.

The following quotation shows how he relates two types of logics, or values, one economic, the other non-economic:

In an economy which is defined by the refusal to recognize the 'objective' truth of 'economic' practices, that is, the law of 'naked self-interest' and egoistic calculation, even 'economic' capital cannot act unless it succeeds in being recognized through a conversion that can render 
unrecognizable the true principle of its efficacy. Symbolic capital is this denied capital, recognized as legitimate, that is recognized as capital ... (Bourdieu 1990 [1980], p. 118)

Thus, the relation between economic and symbolic markets can partly be understood in terms of presence or lack of 'exchange rates' between the types of capital that are in motion. It is an empirical question if these rates can be identified or not. Social honor and other forms of symbolic capital can be convertible: 'a conversion of material capital into symbolic capital itself reconvertible into material capital' (Bourdieu 1990 [1980], p. 119, cf. 1996 [1992], p. 142). In this way, these two 'economies' and their values are related.

Sometimes the relation between fields is complicated, but it is in other cases easy to convert the capital valid in the one for the other (and this is easy as long as it is economic capital). Two adjacent fields (as well as two adjacent markets) are usually related, but it may not be possible to convert forms of capital in these fields. Bourdieu informs us about an empirical case: 'Symbolic capital is valid even in the market. A man may enhance his prestige by making a purchase at an exorbitant price, for the sake of his point of honour, just to "show he could do it"" (1990 [1980], p. 119). It may, according to Bourdieu, be enough for a man with much social capital to show up with his face, in order to 'come back with the whole market' (p. 119). Hence, symbolic capital can be used as credit, which of course only can be granted those who have the right credentials, or are known in the network, and only by business situations in which this type of social capital is recognized. This symbolic capital, it must be remembered, is generated outside of the economic market.

Bourdieu, in essence, provides examples of values of art that are in conflict with economic values. ${ }^{8}$ He speaks of a market, but its values are everything but those of capitalism, which boils down to profit accumulation. ${ }^{9}$ It is clear that different values can be in play in different social structures. Below I will show that the same social structure can co-exist with different values.

I claim that configurations are a better way of handling the problem of order, value, and social structure than the propositions by Biggart, White and Bourdieu. I have argued, to sum up, that Biggart's approach is not valid, since the analysis takes place at a level that lacks empirical references. White's approach is strong on social structure, and the idea of configuration could not have been developed without his work. But White has little to say about values. Bourdieu, finally, has much to say about logic of fields, including values, and also some about social structure. Bourdieu's analysis, however, stops at the gate of the market; the two sides of the market are discussed, but he has little to say about the interaction between different fields. A further problem with Bourdieu's analysis is that he puts too much emphasis on social structure and the possibility of dominating firms to set the 'tempo of transformation in the various areas of production, marketing, research, etc' (2005, p. 2002). His analysis of actors, especially firms, as aggregates of forms of capital (cf. 2005 , p. 194) is less convincing since this cannot easily be translated to something like an identity, which is both a pole of action and of orientation.

\section{Examples of configurations}

I will now exemplify the two forms of social structure, which are combined with values and shown in a total of four examples of configurations. ${ }^{10}$ The examples of configurations show that the same social structure, i.e. structure of roles, can be driven by different values. The examples included address economic issues and capitalistic values, but due to lack of space I will keep them short. 
Configurations aim to simultaneously analyze social structure, value, and social order. Configurations refer to concrete empirical phenomena, and this means that they are partly defined in terms of culture. Culture is here viewed broadly, which means that a configuration has a name (e.g. the market for used cars), is associated with a discourse (e.g. tradesmen using a certain language), practice, history (e.g. people referring back to past experiences) and style (e.g. the way market actors present themselves). This makes configurations different from each other. Thus, though there are similarities between the London Stock Exchange and the Paris Bourse, i.e. that both are exchange markets, and that the same capitalistic value underlie both of them, they have, for example, different traditions, rules and practices. Table 1 shows both similarities as well as dissimilarities between types of configurations (though only one empirical example is given in each box).

I begin by discussing two examples of the switch role structure, or in other words, the social structure in which its incumbents only orient themselves to one side of the configuration. Naturally, all examples are somewhat simplified and what I discuss are instances of ideal types; a thicker description would perhaps reveal configurations with more than one value. ${ }^{11}$

\section{The stock exchange}

The stock exchange epitomizes market capitalism, and Walras used the Paris Bourse as a model for his theory (van Daal and Jolink 1993, Kregel 1998), which still is the foundation of the neoclassical economic canon. This is an example of what is called an auction market. Actors, in this case stockbrokers (but the argument holds true also for the actual stock owners), may switch roles between buyers and sellers several times a day in a stock exchange market. ${ }^{12}$ They may even be buying and selling the same stock many times a day. Brokers do not permanently enact roles as buyer or seller, and the identity of an actor in such a market is hence not connected to either of the two sides of the configuration (the market). Moreover, the stock exchange is in many ways impersonal, and though interaction sometimes takes place face-to-face, 'market interactions' are normally represented by face-screen-face interaction. It is enough to say yes or no to the offers on the screen (see Figure 1), which shows the number of buyers and sellers and what prices they are willing to trade at (Table 2 shows transactions). ${ }^{13}$

Figure 1 and Table 2 show how the market may appear from the perspective of a single actor, for example a broker. All market actors can observe the number of stocks that are 'in the market' and the prices, given that the automated market system operates in real time. Furthermore, all members of a stock exchange have access to virtually the same information, and a member may relay this information to her clients, so that they can also operate in real time.

Table 1. Types of social structure and different values in four configurations. The two types of social structure are both identified in terms of roles that have different interest. In the switch role structure actors may switch roles with ease. The fixed role structure means that actors only hold one role in the configuration.

\begin{tabular}{lll}
\hline & & Value \\
\cline { 2 - 3 } Type of role structure & Capitalistic & Non-capitalistic \\
\hline Switch role & Stock exchange & Swap meeting for model railroads \\
Fixed role & Garment producer market & Fair-trade garment producer market \\
\hline
\end{tabular}




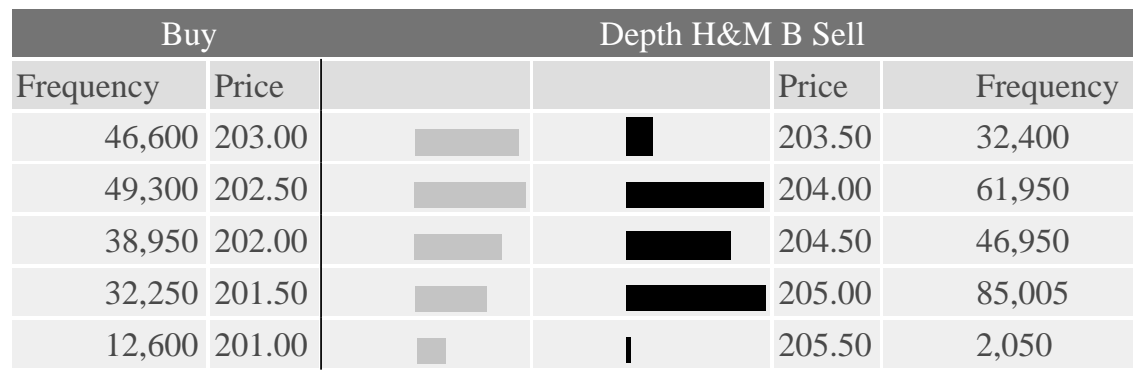

Figure 1. Depth of orders for a single stock at the Stockholm Stock Exchange, H\&M (Series B), 20 February 2004. The bars illustrate the Marshallian graph (though it is not 'perfect', this is no surprise since the graph is only an illustration of the theoretical idea), where buyers and sellers 'meet' (prices in SEK).

Here I present only a very short description of the stock exchange market. This is a socalled switch role market, which fundamentally resembles the idea of how a market operates according to neoclassical theory. What then, is the value in this market? Trade takes place based on the price mechanism, in which of course competition is crucial. The automated mechanism is organized so that you buy and sell, but you do not influence these deals directly; it is guided by the prices sellers are asking, and buyers are bidding. Consequently, the system cannot handle any eventual preferences for signing contract with specific persons.

Obviously, people may endow stock exchange trade with different meanings, but it is clear from the literature (e.g. Abolafia 1996, p. 30, Norberg 2001, Hasselström 2003) that growth of money is a fundamental value for brokers, as well as for their clients. To excel in this market, and to be seen as successful, is to make as much money as possible. This is the fundamental value that can be called capitalistic, which is used for evaluating actors' performance in this configuration. This market, as all markets, is of course also 'kept together' by its culture, recognition of members, the organization that operates the stock exchange, as well as stories and discourse (cf. Smith 1981, Abolafia 1996, Hasselström 2003).

Table 2. Contracts of stocks (H\&M), 20 February 2004. The abbreviations (GSI, INT and so on) indicate the broking firm that has sold or bought stocks for a client. The table also shows the price (SEK), the number of stocks traded, and what time each contract was 'signed'. In this case, one firm, representing clients, NDS, has operated both as buyer and seller. As can be seen, several contracts, between different brokers can be made in the same second.

\begin{tabular}{lccrc}
\hline Price & Buyer & Seller & Amount & Time \\
\hline 203.50 & GSI & INT & 2,000 & $17: 27: 01$ \\
203.50 & NDS & REM & 18,450 & $17: 27: 01$ \\
203.50 & UBS & INT & 4,700 & $17: 27: 01$ \\
203.50 & UBS & LBI & 50 & $17: 27: 01$ \\
203.50 & GSI & OHM & 12,100 & $17: 27: 01$ \\
203.00 & DBL & NDS & 1,400 & $17: 19: 54$ \\
203.00 & DBL & NDS & 2,700 & $17: 19: 29$ \\
203.00 & MSI & NDS & 19 & $17: 19: 25$ \\
203.00 & DBL & AVA & 1,000 & $17: 19: 11$ \\
\hline
\end{tabular}




\section{The swap meeting for model railroads}

A swap meeting is typically a meeting place, which can also be organized on the Internet, where people bring things that they wish to sell, and where they may find things they think are worth buying. Though many attend model-train swap meetings to find a bargain, it is partly also to meet people, see model trains, and the displays (scenes that include running trains). Though some have stalls and bring plenty of trains and cars to a meeting to sell or trade, most do not. There is thus a tendency of division of labor, but most 'sellers' also advertise or are interested in buying; consequently, actors switch sides in the social configuration. This, however, does not affect the social order; it merely indicates that it is a different social structure than in the fixed role structure, to be discussed below.

Thus, people may act in both the buyer and seller roles, and there may not be one single underlying value of the swap meeting. Few, if any actors, take part in railroad modeling with profit as the motive; the majority of those who attend just look around, talk to people, watch the trains running, maybe buy a cargo wagon, and have a cup of tea. This is especially noticeable at the smaller meetings; larger meetings are more for collectors, and large-scale traders (e.g. stores). Moreover, this is a man's world, and though there are some women as well, they are in most cases either daughters or wives of a male train enthusiast. The swap meetings for model railroads are also kept together by the culture of this world: model clubs, magazines and sites on the internet, shows and competition of display, all of which is knitted together by the people who take part.

The value of the exchange structure of a swap meeting cannot be interpreted in a clear way, as the meeting brings together people with different interests. Actors gain credit, or are judged 'successful', according to many different standards: for example, because they have a specialized collection (from a certain time period or manufacturer), or a large one; this differentiates actors in this configuration. The economic interest should be seen as a mediated interest, but the fundamental value system is concentrated on collecting and the running of trains.

I will now discuss two examples of the fixed role structure, but with different values. This is characterized by actors who are fixed to roles on one side of the configuration.

\section{The garment producer market}

Garment producers fix themselves to the role as sellers as they do not operate as buyers of garments. My own research has focused on the global link between garment producers, typically located in developing countries, and retailers, typically located in developed countries (Aspers 2005d). It is usually the buyers, i.e. retailers, who give the calls and determine most of the terms of trades. Moreover, the buyers determine what is produced, including design of the items. There is a culture also in this industry, as well as organizations that represent producers vis-à-vis other collective interests.

Producers differentiate to sign orders with retailers, and the means of differentiation and competition is to have a good price-quality combination. If one performs well, it eventually translates into making more money. In my own studies I have found no evidence that the producers in this industry orient themselves to any other value than profit. Thus, this configuration is at least as competitive as the stock exchange, but these two markets (configurations) represent different forms of social structure. Money is the means for measuring success, and the ultimate value is capitalistic. Hence, the value system in the 
stock exchange and the garment production market are identical, and the difference should primarily be analyzed in terms of different social structure, although also of course in terms of culture i.e. rules, tradition and the like.

\section{The fair-trade garment producer market}

As I have analyzed elsewhere (Aspers 2005c), the fair-trade market represents a similar social structure as the mainstream producer market discussed above. I will here, however, focus on the configuration between the final consumers and the ethical retailers. The retailers have fixed roles as producers and are committed to the values of fair trade, such as improving the conditions of garment workers in developing countries. Actors in the market are members and are scrutinized by organizations, representing this industry, to make sure that they are committed to these values, both in theory and practice. This they do by following the code of conducts that guide and define ethical actors. Such organizations do not only propagate the values the industry holds, but also guide consumers and producers to act ethically. To excel as a retailer in this market is then not to make profit. It is completely accepted that retailers make profit. But unless they provide value for stakeholders outside of the firm, i.e. the producers in developing countries, they are excluded from this configuration. In fact, their success is measured in terms of their added value. Currently, there is no generally accepted way of measuring the success of ethical trade, though it is being developed. ${ }^{14}$

This configuration is a market, because people buy and sell things, and because people in the industry see it as a market. What is demanded is that retailers (buyers) pay 'added value' to the producers, and there are usually further requirements on retailers - for example, helping the producers to develop - and restrictions of the ways one may advertise and so on. All in all, this market represents a value system, which could be called ethical capitalism. The point is that the similar social structure can come with many different values. The analytical tool of configurations, I argue, makes it easier to separate values from structure, though the point of the analysis, of course, is to see how the parts are related to increase our understanding of the field studied.

\section{Discussion}

In this article I have argued, inspired by the works of Bourdieu and White, that what I call social configurations are substantial units of analysis. Configurations are combinations of structure, value and culture. Thus, by separating prices and the economic value measured in prices from underlying values of a configuration (market), i.e. capitalistic and noncapitalistic values, it is possible to better understand differences and similarities between markets.

I argue, in short, that we better understand markets using my approach than the neoclassical analysis, but also than the other approaches discussed here. Though I combine Parsons, Bourdieu and White, I think the idea of configurations is more useful than the ideas of sub-system, fields or molecules. Configurations address the fundamental problem of order, identify the smallest units of order, and include the often neglected idea of values. Moreover, it allows for conflict of interest (e.g. among buyers), while at the same time identifying the underlying value(s) and culture.

There may be many different concrete configurations with the same structure and values, but that nonetheless differ in terms of culture or rules. At a more general level one may say that each configuration is constructed of roles, values and culture. The vehicles of 
the configurations are of course individuals, who bind them together in time through practice, discourse (e.g. in the form of narratives), culture and power relations (e.g. monopoly). Configurations can be seen as 'social islands' of order in a largely uncertain environment. Moreover, configurations have large implications for identity formation (Somers 1994). Identities can be constructed in configuration, and by being named, evaluated and given a position in the social structure, they may become stable. Actors construct configurations in interaction and they may argue about the rules of the game, but configurations also evaluate the performance of actors, which is likely to affect their identities.

There are some open questions that could be addressed in further research. One is that the analysis of this paper is static, and leaves out the dynamics. How, for example, do configurations change? Nor have I analyzed the processes that lead to the different social configurations discussed. These important issues are bracketed, but they are natural factors of a complete analysis. To accomplish this calls for both historical evidence and analysis.

Though this approach opens up an avenue for discussing identity formation, it is still a partial analysis. A general analysis, in which the different configurations are connected, is the aim. Moreover, the interplay between actors and configurations is only alluded to: here actors are just seen as mute incumbents; real actors develop strategies, orient themselves to peers according to their perceptions of social life. More can be done on how order and values are constructed in relation to configurations. Finally, more can also be done on the processes and conflicts that are present in a configuration.

\section{Acknowledgements}

The author gratefully acknowledges that the Axel and Margaret Axson Johnson Foundation financed the research reported here. He thanks Caroline Dahlberg, Ann Vogel, two anonymous reviewers and participants, and especially Sokratis Koniordos, at the Economic Sociology Conference in Rethymno, Crete 2004, for valuable suggestions.

\section{Notes}

1. An individual may constitute a value, but a structured value can only emerge as a result of social interaction. See Joas (1997) for a discussion on the emergence of values, and Husserl (1989 [1913]) for a discussion of the constitution of values.

2. The empirical phenomenological approach (Aspers 2004, 2005a), drawing on Husserl's (1989 [1913]) distinction between natural and spiritual attitude - obviously leaning on the latter - aims at starting the analysis from the perspective of the actors who are studied, and their intentionality (mental directedness).

3. This is not unfounded, since the idea I am using here comes from the works of Harrison White. White $(1981,1992$, p. 31) originally made this distinction between producer markets and exchange markets.

4. Some sociological studies exist of this kind of market (e.g. Knorr Cetina and Brugger 2002, MacKenzie and Millo 2003), though no study has been able to generate a sociological theory of the operation of switch role markets.

5. They operate, however, as buyers in many business-to-business markets, where they buy commodities, such as leather, glue and other components needed for the production of shoes. This they do from suppliers, who are located upstream in the production chain. Actors, consequently, can have different fixed roles in different configurations.

6. Husserl (1975 [1913], §14), though talking from within the phenomenological reduction, has analyzed the process of constitution of values, and he makes an intimate connection between evaluation and value. This connection is also made by Talcott Parsons (1991), p. 38). 
7. Schumpeter, for example, identifies different motives (and values) for becoming an entrepreneur: to found a private kingdom, the will to conquer, and the joy of creating, in addition to the economic motive (Swedberg 2000, p. 16).

8. Bourdieu follows Weber regarding this idea of conflicting values (Bourdieu 1993 [1971], pp. 112 113).

9. It is important, as mentioned above, not to confuse the value of the market with the market value of the products that are later sold. That is, the value of the market for artists is 'art for art's sake' (Bourdieu 1993, p. 198ff), but the products are sold in a market of prices in a currency, such as the Euro.

10. Some examples are built on my own research (participant observation and interviews, $n=27$ ), whereas other examples are based on the existing literature.

11. One may follow Parsons (1954 [1940]) and in detail analyze the values in, for example, the economy in relation to other parts of society; so-called unit acts may reflect different values.

12. Traders can, from a theoretical point of view, be replaced with the owners of the stock.

13. For a more detailed description of how one advanced stock exchange operates, see http:// www.stockholmsborsen.se/handelsinfo/index.asp?lank =1\&lang =eng (accessed 14 December 2005).

14. There are, for example, standards like Social Accountability (SA8000) for monitoring this.

\section{References}

Abolafia, M., 1996. Making markets, opportunism and restraint on Wall Street. Cambridge, MA: Harvard University Press.

Aspers, P., 2004. Empirical phenomenology, an approach for qualitative research. The Methodology Institute, London School of Economics, London (mimeo).

Aspers, P., 2005a. Markets in fashion, a phenomenological approach. London: Routledge.

Aspers, P., 2005b. Markets, sociology of. In: J. Beckert and M. Zafirovski, eds. International encyclopedia of economic sociology. London: Routledge, 427-432.

Aspers, P., 2005c. Ethics in global garment market chains. In: N. Stehr, C. Henning and B. Weiler, eds. The moralization of markets. London: Transaction Press, 289-309.

Aspers, P., 2005d. Status and standard markets in the global garment industry. Max-Planck Institut für Gesellschaftsforschung, Cologne, Discussion Paper 05/10.

Becker, H., Geer, B., Hughes, E. and Strauss, A., 1961. Boys in white: student culture in medical school. New Brunswick: Transaction.

Berger, P. and Luckmann, T., 1966. The social construction of reality. New York: Anchor Books.

Biggart, N. and Delbridge, R., 2004. Systems of exchange. Academy of management review, 29 (1), 28 49.

Bourdieu, P., 1984 [1979]. Distinction: a social critique of the judgment of taste. Cambridge, MA: Harvard University Press.

Bourdieu, P., 1990 [1980]. The logic of practice. Cambridge: Polity Press.

Bourdieu, P., 1990 [1987]. In other words: essays towards a reflexive sociology. Cambridge: Polity Press.

Bourdieu, P., 1993. The fields of cultural production: essays on art and literature. Oxford: Polity Press.

Bourdieu, P., 1993 [1971]. The market for symbolic goods. In: The fields of cultural production: essays on art and literature. Cambridge: Polity Press, 112-141.

Bourdieu, P., 1996 [1992]. The rules of art: genesis and structure of the literary field. Stanford: Stanford University Press.

Bourdieu, P., 2001 [1983]. The forms of capital. In: M. Granovetter and R. Swedberg, eds. The sociology of economic life. Boulder: Westview, 96-111.

Bourdieu, P., 2005. The social structures of the economy. Cambridge: Polity Press.

Bourdieu, P. and Wacquant, L., 2002 [1992]. An invitation to reflexive sociology. Oxford: Polity.

Burt, R., 1992. Structural holes. The social structure of competition. Cambridge, MA: Harvard University Press.

Devereux, E., 1961. 'Parsons' sociological theory. In: M. Black, ed. The social theories of Talcott Parsons: a critical examination. Englewood Cliffs: Prentice Hall, 1-63. 
Eisenstadt, S., 1968. The development of sociological thought. In: D. Sills, ed. International encyclopedia of the social sciences, Vol. 15. London: Macmillan, 23-36.

Emirbayer, M. and Goodwin, J., 1994. Network analysis, culture, and the problem of agency. American journal of sociology, 99 (6), 1411-1454.

Fevre, R., 2003. The new sociology of economic behaviour. London: Sage.

Gudeman, S., 2001. The anthropology of economy. Oxford: Blackwell.

Hasselström, A., 2003. On and off the trading floor: an inquiry into the everyday fashioning of financial market knowledge. Department of Social Anthropology, Stockholm University, Stockholm (mimeo).

Husserl, E., 1970 [1954]. The crisis of European sciences and transcendental phenomenology. Evanston: Northwestern University Press.

Husserl, E., 1975 [1913]. Logische Untersuchungen, Erster Band, Prologomena zur reinen Logic (Husserliana 18). The Hauge: Martinus Nijhoff.

Husserl, E., 1989 [1913]. Ideas pertaining to a pure phenomenology and to a phenomenological philosophy, Second Book, Studies in the Phenomenology of Constitution. Dordrecht: Kluwer.

Joas, H., 1997. Die Entstehung der Werte. Frankfurt am main: Surkamp.

Knorr Cetina, K. and Bruegger, U., 2002. Global microstructures: the virtual societies of financial markets. American journal of sociology, 107 (4), 905-950.

Kregel, J., 1998. Financial markets and economic development: myth and institutional reality. In: K. Nielsen and B. Johansson, eds. Institutions and economic change, new perspectives on markets, firms and technology. Cheltenham: Edward Elgar, 243-257.

Lidz, V., 1991. The American value system. In: R. Robertson and B. Turner, eds. Talcott Parsons, theorist of modernity. London: Sage, 22-36.

Luhmann, N., 1982. The differentiation of society. New York: Columbia University Press.

Luhmann, N., 1995 [1984]. Social systems. Stanford: Stanford University Press.

MacKenzie, D. and Millo, Y., 2003. Constructing a market, performing theory: the historical sociology of a financial derivatives exchange. American journal of sociology, 109 (1), 107-145.

Norberg, P., 2001. Finansmarknadens amoralitet och det kalvinistiska kyrkorummet: en studie $i$ ekonomisk mentalitet och etik. Stockholm: Ekonomiska forskningsinstitutet vid Handelshögskolan.

Parsons, T., 1954 [1940]. The motivation of economic activities. In: T. Parsons. Essays in sociological theory. New York: The Free Press, 50-68.

Parsons, T., 1961. The point of view of the author. In: M. Black, ed. The social theories of Talcott Parsons: a critical examination. Englewood Cliffs: Prentice Hall, 311-363.

Parsons, T., 1991. A tentative outline of American values. In: R. Robertson and B. Turner, eds. Talcott Parsons, theorist of modernity. London: Sage, 37-65.

Polanyi, K., 1957. The economy as instituted process. In: K. Polanyi, C. Arensberg and H. Pearson, eds. Trade and market in the early empires: economies in history and theory. New York: The Free Press, 12-26.

Radcliffe-Brown, A.R., 1952. Structure and function in primitive society: essays and addresses. London: Cohen and West.

Schumpeter, J., 1981 [1954]. History of economic analysis. London: Routledge.

Smith, C., 1981. The mind of the market: a study of stock market philosophies, their use, and their implication. Totowa: Rowman and Littlefield.

Somers, M., 1994. The narrative constitution of identity: a relational and network approach. Theory and society, 23, 605-649.

Swedberg, R., 1998. Max Weber and the idea of economic sociology. Princeton NJ: Princeton University Press.

Swedberg, R., 2000. The social science view of entrepreneurship: introduction and practical applications. In: R. Swedberg, ed. Entrepreneurship. The social science view. Oxford: Oxford University Press, 7-44.

Van Daal, J. and Jolink, A., 1993. The equilibrium economics of Leon Walras. London: Routledge

Weber, M., 1946. From Max Weber: essays in sociology, eds H. Gerth and C.W. Mills. London: Routledge.

Weber, M., 1968 [1904-1905]. The protestant ethic and the spirit of capitalism. London: Unwin University Books. 
Weber, M., 1978 [1921-1922]. Economy and society: an outline of interpretive sociology, eds G. Roth and C. Wittich, 2 vols. Berkeley: University of California Press.

White, H., 1981. Where do markets come from? American journal of sociology, 87 (3), 517-547.

White, H., 1992. Identity and control: a structural theory of social action. Princeton: Princeton University Press.

White, H., 2002. Markets from networks: socioeconomic models of production. Princeton: Princeton University Press.

Zelizer, V., 1989. The social meaning of money: 'special monies'. The American journal of sociology, 95 (2), 342-377. 